\title{
Clinical presentation and outcome of pediatric ANCA-associated glomerulonephritis
}

Anne M. Kouri and Sharon P. Andreoli

Indiana University School of Medicine

Department of Pediatric Nephrology

699 Riley Hospital Drive, Rm 230

Indianapolis, IN 46202

Corresponding author:

Anne M. Kouri, MD

akouri@iupui.edu

This is the author's manuscript of the article published in final edited form as:

Kouri, A. M., \& Andreoli, S. P. (2017). Clinical presentation and outcome of pediatric ANCA-associated glomerulonephritis. Pediatric Nephrology, 32(3), 449-455. https://doi.org/10.1007/s00467-016-3490-6 


\begin{abstract}
Introduction: Anti-neutrophil cytoplasmic antibody (ANCA)-associated vasculitis is a small- and medium-sized vasculitis classically seen in adult patients with peak onset near the fifth to seventh decade of life. There is little data on ANCA-associated vasculitis in pediatric patients and most studies have limited follow-up.
\end{abstract}

Methods: This is a retrospective chart review of 22 patients in a single institution from 1991 to 2013.

Results: Of the 22 patients in our institution with ANCA-positive glomerulonephritis, eight patients (36\%) required renal replacement therapy (RRT) at diagnosis; four of these patients recovered sufficient renal function to initially discontinue dialysis. Five patients $(23 \%)$ were treated with plasmapheresis at presentation. The median time from presentation until first clinical or serologic relapse was $1.7 \pm 1.2$ years. After a median follow-up of 5.8 years, just over half of our patients have chronic kidney disease (CKD) stages 1-3 (55\%). Seven (32\%) patients progressed to end-stage renal disease (ESRD) and eventually required kidney transplant.

Conclusion: ANCA-associated glomerulonephritis is a rare disorder in children. Presentation and outcomes vary significantly amongst patients. More research is required to follow these patients who are diagnosed in childhood to further characterize the long term outcome of the disease. 


\section{KEYWORDS:}

ANCA-positive glomerulonephritis; Rapidly-progressive glomerulonephritis; Pediatric glomerulonephritis; Granulomatosis with polyangiitis; Microscopic polyangiitis; Children

\section{ABBREVIATIONS:}

AAV: ANCA-associated vasculitis

ANCA: Anti-neutrophil cytoplasmic antibody

AGN: ANCA-associated glomerulonephritis classification

c-ANCA: cytoplasmic anti-neutrophil cytoplasmic antibody

CKD: Chronic kidney disease

ESRD: End stage renal disease

EPA: Eosinophilic granulomatosis with polyangiitis

GFR: Glomerular filtration rate

GPA: Granulomatosis with polyangiitis

MPA: Microscopic polyangiitis

MPO: Myeloperoxidase

PR3: Proteinase 3

p-ANCA: perinuclear anti-neutrophil cytoplasmic antibody

RPGN: Rapidly progressing glomerulonephritis

RRT: Renal replacement therapy 


\section{INTRODUCTION}

Dr. J. Charles Jennette and Dr. Ronald J. Falk first characterized the association of anti-neutrophil cytoplasmic antibodies (ANCA) with necrotizing vasculitis in the 1980s and 1990s [1]. ANCA-associated vasculitis (AAV) is a small- and medium-sized vasculitis which has since been classified in to three separate entities: granulomatosis with polyangiitis (GPA, formerly Wegener's granulomatosis), microscopic polyangiitis (MPA) and eosinophilic granulomatosis with polyangiits (EGPA) [2]. It is a disease classically seen in adults and is rare in the pediatric population. The peak age of onset is commonly between the fifth and seventh decade of life [3]. As a result, much of the data and treatment protocols are extrapolated from adult data and applied to pediatric patients.

The data on ANCA-associated renal disease in children is mostly in the form of case series and retrospective studies with limited follow-up. Similar to other childhood chronic diseases, children with AAV differ from adults in that they have a longer anticipated life span over which their disease must be managed. The peak age of onset of $\mathrm{AAV}$ in the pediatric population is during late childhood and adolescence, a critical time for growth as well as emotional, physical and reproductive development [4-6]. Critical therapeutic decisions must be made to maximize quality of life as well as longterm renal and overall survival. Thus, longitudinal data in this patient population is needed to see the potential evolution of disease through childhood, adolescence and into adulthood. 
The purpose of this study is to describe pediatric ANCA-associated glomerulonephritis at a single center and to compare our experience with previously published adult and pediatric literature.

\section{METHODS}

This study was approved by the Institutional Review Board (IRB) governing Indiana University School of Medicine. It is a retrospective chart review of 22 patients with ANCA-positive glomerulonephritis diagnosed or managed from 1991 to 2013 within the Pediatric Nephrology and Hypertension Division at Riley Hospital for Children at Indiana University Health, a tertiary care center with a pediatric nephrology division in addition to other pediatric subspecialties. The IRB granted a waiver of consent for this study. We identified patients from the GE-Centricity Business (IDX) billing system based on ICD-9 codes available to our institution for billing. The following codes generated a list of 213 patients: 446.0 polyarteritis nodosa and allied conditions, 580.4 acute glomerulonephritis, 582.0 chronic glomerulonephritis, 584.5 acute kidney failure with tubular necrosis, and 584.9 acute kidney failure. From this list, 23 patients were identified as ANCA-positive. One patient was ANCA-positive but upon further review had questionable renal involvement and was excluded. In total, 22 patients with ANCApositive disease and active renal involvement were included in the study.

Patients were selected if they met the following criteria: (1) ANCA-positive serology with clinical renal involvement and/or (2) biopsy findings consistent with the diagnosis of ANCA-positive glomerulonephritis. Charts were reviewed for demographic information as well as clinical and laboratory characteristics at presentation, relapse and 
most recent follow-up. The patients were considered to have suffered a serologic relapse if their ANCA titer started to rise after a previous period of stability or became positive after having been negative. Patients were considered to have had a clinical relapse if they developed symptoms that required changes in medical therapy. The estimated glomerular filtration rate for each patient was calculated using the modified Schwartz equation [7]. Length of follow-up was determined from the time of presentation to the time of transplant or to the time of most recent follow-up for those patients who did not progress to end-stage renal disease (ESRD) or to the date of most recent available clinical information. All patients who progressed to ESRD were transplanted.

\section{Statistics}

Statistical analysis was performed using IBM SPSS 23® statistical software. Continuous variables were compared using the Mann-Whitney-U test.

\section{RESULTS}

Demographic information

A total of 1017 unique patients were diagnosed with glomerulonephritis from 1991 to 2013 at our institution; 22 patients were identified as having ANCA-positive glomerulonephritis, making the proportion of patients with ANCA-associated glomerulonephritis $2.16 \%$. Of the 22 patients in our institution with ANCA-positive glomerulonephritis, 13 patients (59\%) were female. The median age at presentation was 13.7 years (IQR 11.6-15.7). Males presented at an older age than females, but 
this was not statistically significant $(p=0.08)$. See Table 1 for a summary of patient demographics and presenting characteristics.

\section{Clinical presentation and initial treatment}

Twenty of 22 patients had documented systemic symptoms reported at presentation. Diagnosis and initial management took place at outside institutions for two patients. Figure 1 characterizes the percentage of patients with the most common presenting symptoms. The most commonly reported symptoms were respiratory in nature, with $55 \%$ of patients having documented pulmonary or sinus involvement. Other patients presented with non-specific complaints of body aches, malaise and fatigue. One patient presented with heart failure requiring ionotropic support.

The renal involvement at presentation varied considerably, details of which are shown in Table 1. All of our patients presented with hematuria, proteinuria or both. Renal biopsy was performed on 21 patients, 19 of which were performed at our institution. One patient did not have a biopsy performed due to the critical nature of the patient's condition at presentation. We classified the renal biopsies into the most appropriate histopathologic categories: focal, crescentic, mixed, and sclerotic according to the ANCA-associated glomerulonephritis (AGN) classification [8-10].

Of the twenty patients initially diagnosed and managed at our hospital, all were treated with varying regimens at presentation. Every patient received a methylprednisolone pulse (500 $\mathrm{mg}$ to $2000 \mathrm{mg}$ per dose), varying between 2 and 6 doses over 2 to 12 days. Following administration of pulse-dose steroids, each of the 
patients was transitioned to oral prednisone at $2 \mathrm{mg} / \mathrm{kg} / \mathrm{day}$ up to a maximum dose of $60 \mathrm{mg} /$ day. With the exception of four patients, all patients were treated with either oral or IV cyclophosphamide. Maintenance immunosuppression for each individual patient was left to the discretion of the treating physician and therefore no standard protocol was used. However, maintenance therapy often consisted of a combination of prednisone with another agent including mycophenalate mofetil, azathioprine, or hydroxychloroquine. One patient was treated with twice weekly etanercept injections.

Eight patients $(36 \%)$ required renal replacement therapy (RRT) at the time of initial presentation; four of these patients recovered sufficient renal function to discontinue dialysis. Five patients $(23 \%)$ were treated with plasmapheresis at presentation. The decision to perform plasmapheresis was at the discretion of the attending nephrologist and generally was reserved for those with the most severe disease at presentation or those who had a slow response to initial therapy. One patient who required plasmapheresis did not require concurrent RRT; three years following diagnosis, this patient remains off RRT with CKD stage 3. Of the remaining four patients who required RRT and were treated with plasmapheresis, two patients recovered renal function. One was able to discontinue continuous veno-venous hemofiltration after 25 days. The other patient's dialysis duration was unavailable. They were both able to remain off dialysis at most recent follow-up with CKD Stage 2 at 3 and 6 years following diagnosis.

Failure of induction therapy and relapse 
Following induction therapy, two of our patients (9\%) did not successfully enter remission. One patient was treated with methylprednisolone pulses as well as weekly methotrexate, intravenous cyclophosphamide in addition to hydroxychloroquine but ultimately died in the acute phase of the illness. In the days leading to up to death, the cyclophosphamide and methotrexate were discontinued due to persistent neutropenia. The patient eventually succumbed to complications of pulmonary fibrosis. The other patient who failed induction therapy was treated with methylprednisolone, intravenous cyclophosphamide, azathioprine, mycophenolate mofetil and required dialysis and eventually kidney transplantation.

Twelve patients (55\%) experienced at least one serologic or clinical relapse. Of these patients, 9 suffered from solely serologic relapses, 2 experienced serologic relapses associated with clinical symptoms, and 1 patient had a documented clinical relapse without evidence of serologic relapse. The median length of time from presentation until first clinical or serologic relapse was 1.7 years (IQR 1.0-2.2). Figure 2 is a Kaplan-Meier curve illustrating the relapse-free survival for all 22 patients. At least 8 patients $(67 \%)$ suffered their first relapse while on immunosuppressive medication. Of these 8 patients, 3 patients relapsed while on mycophenolate mofetil in combination with prednisone, 1 on azathioprine in combination with every-other-day prednisone (40 $\mathrm{mg}$ ), 1 on cyclophosphamide in combination with daily prednisone $(5 \mathrm{mg})$, and 3 relapsed while on every-other-day prednisone (50 mg, $30 \mathrm{mg}, 5 \mathrm{mg})$. Seven patients (32\%) experienced more than one relapse.

All 3 patients with a confirmed clinical component to his or her first relapse were treated with increases in immunosuppression, including increases in prednisone and 
mycophenolate mofetil, and in the case of 1 patient, with the initiation of high-dose methylprednisolone and cyclophosphamide. Despite aggressive treatment, two of these patients progressed to ESRD.

Not all serologic relapses were treated with increases in immunosuppressive therapy. Four patients with first-time serologic relapses were documented to have had increases in immunosuppression prescribed by their provider. There was no standardized treatment protocol for treatment of clinical or serologic relapse, so it is difficult to draw conclusions regarding treatment efficacy based on our data.

\section{ESRD and transplant}

The median length of time to follow-up for all patients was 5.8 years (IQR 3.08.3). Two patients were lost to follow-up. Seven (32 \%) patients progressed to ESRD and required kidney transplant. Median estimated glomerular filtration rate at most recent follow-up of those patients who did not progress to ESRD was 61.1 $\mathrm{mL} / \mathrm{min} / 1.73 \mathrm{~m}^{2}$ (IQR 49.3-78.0). The median time from presentation to kidney transplant was 3.5 years (IQR 2.0-8.3).

Table 2 illustrates the renal outcomes for our patients. Of the eight patients that required dialysis at presentation, five patients $(63 \%)$ progressed to require kidney transplantation. The median creatinine at presentation for those patients who did eventually progress to ESRD was $8.85 \mathrm{mg} / \mathrm{dL}$ (IQR 2.4-28.9). The creatinine of those patients who did not progress to ESRD overall trended lower at presentation with a 
median of $2.2 \mathrm{mg} / \mathrm{dL}$ (IQR $0.9-5.6$ ). However, this difference was not statistically significant.

Two patients who progressed to ESRD did not present with a need for dialysis. For those 2 patients, the serum creatinine at presentation was $1.5 \mathrm{mg} / \mathrm{dL}$ and $2.7 \mathrm{mg} / \mathrm{dL}$ at ages 17.4 years and 11.1 years, respectively; one patient was PR3-positive at presentation while the other patient was actually ANCA negative at presentation and later seroconverted to MPO-positive disease. One of these patients actually failed induction therapy, and the other patient had frequently-relapsing disease with subsequent decline in renal function. No patients in our study have had the rare, but reported, complication of recurrence of disease in the transplanted kidney.

\section{DISCUSSION}

This is one of the largest studies to describe ANCA-positive glomerular disease in children with one of the longest follow-up durations to date. To our knowledge, there are only a handful of recent retrospective studies that describe clinical characteristics of children with this disease; data are sparse in terms of long-term follow-up and progression to ESRD. Table 3 is a summary of previously published data on pediatric AAV with or without renal involvement. In addition, we determined that ANCA-positive glomerulonephritis accounted for $2.16 \%$ of cases of glomerulonephritis at our center, documenting that ANCA-positive glomerulonephritis is rare in pediatric patients.

Our patient demographics are consistent with what has been previously reported in the pediatric literature, with peak age of onset during adolescence and a female- 
predominant patient population $[5,11-14]$. In the adult literature, it is reported that renal involvement in AAV can be so severe as to require dialysis-dependence in $23-60 \%$ of these patients $[15,16]$. Our study found that $36 \%$ of patients required dialysis at diagnosis, which is within the range previously reported in the pediatric literature as well $[5,6,10-13,17-21]$. However, it is important to note that our study is based solely on those patients with renal involvement and does not include patients without renal involvement. This can be misleading when comparing our study to others, as $100 \%$ of our patients suffered from renal involvement and therefore represent the population who is at the highest risk for dialysis.

Even with effective therapies, AAV is a chronic illness. In adults, AAV has been reported to have a $90 \%$ two-year mortality if left untreated. Modern treatment protocols with high dose steroids, cyclophosphamide, rituximab and plasmapheresis have improved the prognosis of this disease, but all are also associated with significant morbidities. Also in adult populations, it is documented that induction therapy fails to induce remission in approximately $10 \%$ of patients [3]. Moreover, after induction therapy and remission, many patients suffer from clinical or serologic relapse, and kidney function has been reported to be inversely associated with relapse rate [22].

Our study's pediatric data is strikingly similar to the adult data with respect to induction therapy and relapsing disease. Ten percent of patients in our study failed to respond to initial therapy and over half $(55 \%)$ of patients suffered from clinical or serologic relapse. Our data also suggest that patients who fail to enter remission with induction therapy and those who have more frequent relapses have a worse renal outcome. However, our study is biased by the assumption that the time of renal 
involvement was simultaneous with the time of disease onset. This is not always the case for all patients with AAV, as pediatric patients are especially vulnerable to a delay in diagnosis, given the rarity of the disease and variability in presenting signs and symptoms $[14,23]$. In addition, the relapse rate in our study is rather high $(55 \%)$. This may be a function of the follow-up time of the study, with ANCA titers known to fluctuate in individual patients without evidence of clinical disease. Current guidelines do not consider solely a change in ANCA titer a relapse, but rather a time for close clinical and laboratory monitoring in an individual patient.

With regards to overall prognosis, the adult literature reports that older age, female gender, higher serum creatinine and chronic histologic lesions are predictors for worse renal outcome and overall survival [16]. Fourteen to 18 percent of adult patients with AAV require permanent dialysis and the disease has a 23-40\% mortality rate by 1 and 5 years from diagnosis $[16,24]$. In our pediatric cohort, the data also suggests that a higher creatinine at presentation is a negative prognostic factor in terms of renal prognosis, although our results were not statistically significant likely due to the sample size. However, the overall renal prognosis and survival is arguably better than that of the adult population despite the fact that seven of our patients (32\%) progressed to ESRD and required a kidney transplant. Just over half of our patients have CKD stages 1-3 (55\%) with the median estimated glomerular filtration rate of $61.1 \mathrm{ml} / \mathrm{min} / 1.73 \mathrm{~m}^{2}$ for those patients who did not progress to ESRD at a median of 5.8 years following diagnosis. The mortality rate in our study was much lower (1 patient, $5 \%$ ) than what has been reported in the adult literature. Additionally, nearly two-thirds of our sample had relatively indolent courses and had no need for RRT. 
This study is a retrospective chart review. As for all studies with this design, there are significant biases and limitations. These limitations should not be undermined. For example, documented rises in ANCA titers may have been associated with more clinical symptoms which were not clearly documented in the paper or electronic medical record, limiting our ability to truly document a clinical versus a serologic relapse in these patients. In addition, two patients were diagnosed at outside institutions and therefore the information surrounding their presentation is limited. Additionally, a statistic illustrating the duration from presentation to ESRD in the patients who developed ESRD would have been helpful. However, the data collection was limited by what was available in the chart and the timing of dialysis initiation was not available for most patients.

The sample size of our study is a relative limitation. This disease is uncommon and although we are a fairly high-volume center, approximately 1 patient with this disease presents per year at our institution. Nonetheless, our study has a relatively large cohort with a relatively long follow-up duration when compared to other published pediatric literature on the topic. As such, pediatric patients, in contrast to adults, have potentially multiple decades to live with this disease; understanding this disease over long periods of time is essential for improvement in the care of these patients.

\section{CONCLUSION}

ANCA-positive glomerulonephritis is a rare disorder in children. At presentation, the degree of renal involvement is quite variable, ranging from mild to very severe renal injury. However, nearly two-thirds of our cohort were without need for RRT at a median 
follow-up time of 5.8 years, indicating that with modern therapies this disease can be indolent despite the risk of relapse. Nonetheless, more prospective research is required to understand the disease progression in children.

Conflict of interest: The authors have no conflicts of interest to disclose.

Ethics: This study was approved by the Institutional Review Board governing Indiana University School of Medicine. A waiver of consent was granted for this study. 


\section{REFERENCES}

1. Jennette JC, Falk RJ (1990) Antineutrophil cytoplasmic autoantibodies and associated diseases: a review. Am J Kidney Dis 6:517-529

2. Kallenberg CG, Stegeman CA, Abdulahad WH, Heeringa P (2013) Pathogenesis of ANCA-associated vasculitis: new possibilities for intervention. Am J Kidney Dis 6:11761187

3. Kamesh L, Harper L, Savage CO (2002) ANCA-positive vasculitis. J Am Soc Nephrol 7:1953-1960

4. Bohm M, Gonzalez Fernandez MI, Ozen S, Pistorio A, Dolezalova P, Brogan P, Barbano G, Sengler C, Klein-Gitelman M, Quartier P, Fasth A, Herlin T, Terreri MT, Nielsen S, van Rossum MA, Avcin T, Castell ER, Foeldvari I, Foell D, Kondi A, KonePaut I, Kuester RM, Michels H, Wulffraat N, Amer HB, Malattia C, Martini A, Ruperto N (2014) Clinical features of childhood granulomatosis with polyangiitis (wegener's granulomatosis). Pediatr Rheumatol Online J 12:18

5. Hattori M, Kurayama H, Koitabashi Y; Japanese Society for Pediatric Nephrology (2001) Antineutrophil cytoplasmic autoantibody-associated glomerulonephritis in children. J Am Soc Nephrol 7:1493-1500

6. Peco-Antic A, Bonaci-Nikolic B, Basta-Jovanovic G, Kostic M, Markovic-Lipkovski J, Nikolic M, Spasojevic B (2006) Childhood microscopic polyangiitis associated with MPO-ANCA. Pediatr Nephrol 1:46-53 
7. Schwartz GJ, Haycock GB, Edelmann CM, Jr., Spitzer A (1976) A simple estimate of glomerular filtration rate in children derived from body length and plasma creatinine. Pediatrics 2:259-263

8. Berden AE, Ferrario F, Hagen EC, Jayne DR, Jennette JC, Joh K, Neumann I, Noel LH, Pusey CD, Waldherr R, Bruijn JA, Bajema IM (2010) Histopathologic classification of ANCA-associated glomerulonephritis. J Am Soc Nephrol 10:1628-1636

9. Ford SL, Polkinghorne KR, Longano A, Dowling J, Dayan S, Kerr PG, Holdsworth SR, Kitching AR, Summers SA (2014) Histopathologic and clinical predictors of kidney outcomes in ANCA-associated vasculitis. Am J Kidney Dis 2:227-235

10. Noone DG, Twilt M, Hayes WN, Thorner PS, Benseler S, Laxer RM, Parekh RS, Hebert D (2014) The new histopathologic classification of ANCA-associated GN and its association with renal outcomes in childhood. Clin J Am Soc Nephrol 10:1684-1691

11. Belostotsky VM, Shah V, Dillon MJ (2002) Clinical features in 17 paediatric patients with Wegener granulomatosis. Pediatr Nephrol 9:754-761

12. Arulkumaran N, Jawad S, Smith SW, Harper L, Brogan P, Pusey CD, Salama AD (2011) Long-term outcome of paediatric patients with ANCA vasculitis. Pediatr Rheumatol Online J 9:12

13. Siomou E, Tramma D, Bowen C, Milford DV (2012) ANCA-associated glomerulonephritis/systemic vasculitis in childhood: clinical features-outcome. Pediatr Nephrol 10:1911-1920 
14. Yu F, Huang JP, Zou WZ, Zhao MH (2006) The clinical features of anti-neutrophil cytoplasmic antibody-associated systemic vasculitis in Chinese children. Pediatr Nephrol 4:497-502

15. de Joode AA, Sanders JS, Stegeman CA (2013) Renal survival in proteinase 3 and myeloperoxidase ANCA-associated systemic vasculitis. Clin J Am Soc Nephrol 10:1709-1717

16. Sinico RA, Di Toma L, Radice A (2013) Renal involvement in anti-neutrophil cytoplasmic autoantibody associated vasculitis. Autoimmun Rev 4:477-48217. Krmar RT, Kagebrand M, Hansson ME, Halling SE, Asling-Monemi K, Herthelius M, Holtback U, Christensson M, Wernerson A, Bruchfeld A (2013) Renal-limited vasculitis in children: a single-center retrospective long-term follow-up analysis. Clin Nephrol 5:388394

18. Akikusa JD, Schneider R, Harvey EA, Hebert D, Thorner PS, Laxer RM, Silverman ED (2007) Clinical features and outcome of pediatric Wegener's granulomatosis. Arthritis Rheum 5:837-844

19. Basu B, Mahapatra TK, Mondal N (2015) Favourable renal survival in paediatric microscopic polyangiitis: efficacy of a novel treatment algorithm. Nephrol Dial Transplant 30 Suppl 1:i113-118

20. Sacri AS, Chambaraud T, Ranchin B, Florkin B, See H, Decramer S, Flodrops H, Ulinski T, Allain-Launay E, Boyer O, Dunand O, Fischbach M, Hachulla E, Pietrement C, Le Pogamp P, Stephan JL, Belot A, Nivet H, Nobili F, Guillevin L, Quartier P, Deschenes G, Salomon R, Essig M, Harambat J (2015) Clinical characteristics and 
outcomes of childhood-onset ANCA-associated vasculitis: a French nationwide study. Nephrol Dial Transplant 30 Suppl 1:i104-112

21. Valentini RP, Smoyer WE, Sedman AB, Kershaw DB, Gregory MJ, Bunchman TE (1998) Outcome of antineutrophil cytoplasmic autoantibodies-positive glomerulonephritis and vasculitis in children: a single-center experience. J Pediatr 2:325-328

22. Walsh M, Flossmann O, Berden A, Westman K, Hoglund P, Stegeman C, Jayne D; European Vasculitis Study Group (2012) Risk factors for relapse of antineutrophil cytoplasmic antibody-associated vasculitis. Arthritis Rheum 2:542-548

23. Ellis EN, Wood EG, Berry P (1995) Spectrum of disease associated with antineutrophil cytoplasmic autoantibodies in pediatric patients. J Pediatr 1:40-43

24. Day CJ, Howie AJ, Nightingale P, Shabir S, Adu D, Savage CO, Hewins P (2010) Prediction of ESRD in pauci-immune necrotizing glomerulonephritis: quantitative histomorphometric assessment and serum creatinine. Am J Kidney Dis 2:250-258

25. Bakkaloglu A, Ozen S, Baskin E, Besbas N, Gur-Guven A, Kasapcopur O, Tinaztepe K (2001) The significance of antineutrophil cytoplasmic antibody in microscopic polyangitis and classic polyarteritis nodosa. Arch Dis Child 5:427-430

26. Cabral DA, Uribe AG, Benseler S, O'Neil KM, Hashkes PJ, Higgins G, Zeft AS, Lovell DJ, Kingsbury DJ, Stevens A, McCurdy D, Chira P, Abramson L, Arkachaisri T, Campillo S, Eberhard A, Hersh AO, Huber AM, Kim S, Klein-Gitelman M, Levy DM, Li SC, Mason T, Dewitt EM, Muscal E, Nassi L, Reiff A, Schikler K, Singer NG, Wahezi D, Woodward A; ARChiVe (A Registry for Childhood Vasculitis: e-entry) Investigators 
Network (2009) Classification, presentation, and initial treatment of Wegener's granulomatosis in childhood. Arthritis Rheum 11:3413-3424

27. Khalighi MA, Wang S, Henriksen KJ, Bock M, Keswani M, Chang A, Meehan SM (2015) Pauci-immune glomerulonephritis in children: a clinicopathologic study of 21 patients. Pediatr Nephrol 6:953-959 


\section{LIST OF TABLES:}

Table 1: Summary of Patient Characteristics at Presentation

$B U N$ : blood urea nitrogen, IQR: interquartile range

Table 2: Renal Outcomes at Median Follow-up of 5.8 years

CKD: chronic kidney disease, eGFR: estimated glomerular filtration rate, ESRD: endstage renal disease, Tx: transplantation

Table 3: Summary of Literature Reported on ANCA-Positive Glomerulonephritis

\section{LIST OF FIGURES:}

Figure 1: Systemic Symptoms at Presentation of Patients with ANCA-Positive Glomerulonephritis

Figure 2: Kaplan-Meier Curve Illustrating Relapse-Free Survival $f$ or Patients with FirstTime Clinical or Serologic Relapse 

Gender [n(\%)]
Male
$9(41)$
Female
$13(59)$
Age (Median in years)
13.7 (IQR 4.2)
Male 15.6 (IQR 3.6)
Female 11.9 (IQR 4.8)

$\underline{\text { Serology }[\mathrm{n}(\%)]}$ c-ANCA/PR3 $9(41)$

p-ANCA/MPO $9(41)$

c-ANCA $0(0)$

p-ANCA $1(4.5)$

PR3 $0(0)$

MPO

Both $1(4.5)$

Other 1 (4.5) (Initially negative, then seroconverted to p-ANCA)

Median BUN

$\underline{(\mathrm{mg} / \mathrm{dL})}$ $40.5(\text { IQR 52) })^{1}$

Median Creatinine $\underline{(\mathrm{mg} / \mathrm{dL})}$ $2.7(\mathrm{IQR} 5.4)^{2}$

$\%$ with Hematuria $100 \%$

$\%$ with Proteinuria $100 \%$

Median Protein:Creatinine (mg/mg) $1.5(\mathrm{IQR} 4.1)^{3}$

$\underline{\text { Pathologic Findings on Biopsy }[\mathrm{n}(\%)]^{4}}$

Focal $0(0)$

Crescentic $10(53)$

Mixed $4(21)$

Sclerotic $5(26)$

$\underline{\text { Table 1: Summary of Patient Characteristics at Presentation }}$

${ }^{1} 20$ of 22 patients have BUN reported at presentation

221 of 22 patients have creatinine reported at presentation

${ }^{3} 14$ of 22 patients have $\mathrm{Pr} / \mathrm{Cr}$ ratios reported at presentation

${ }^{4} 2$ biopsies at outside institutions not included in classification 


\begin{tabular}{|c|c|}
\hline CKD $1\left(\right.$ eGFR > $\left.90 \mathrm{~mL} / \mathrm{min} / 1.73 \mathrm{~m}^{2}\right)$ & 6 \\
\hline CKD 2 (eGFR 60-89 mL/min/1.73m²) & 3 \\
\hline CKD 3 (eGFR 30-59 mL/min/1.73m²) & 3 \\
\hline $\begin{array}{c}\text { CKD 5/ESRD/Tx (eGFR }<15 \\
\mathrm{~mL} / \mathrm{min} / 1.73 \mathrm{~m}^{2} \text { or dialysis) }\end{array}$ & 7 \\
\hline Lost to follow-up & 2 \\
\hline Deceased & 1 \\
\hline TOTAL & 22 \\
\hline
\end{tabular}

Table 2: Renal Outcomes at Median Follow-up of 5.8 years 


\begin{tabular}{|c|c|c|c|c|c|c|c|c|c|c|c|c|c|c|c|c|c|c|}
\hline & & $\begin{array}{c}\text { Ellis } \\
1995 \text { [23] }\end{array}$ & $\begin{array}{l}\text { Valentini } \\
1998[21]\end{array}$ & $\begin{array}{l}\text { Bakkaloglu } \\
2001[25]\end{array}$ & $\begin{array}{l}\text { Hattori } \\
2001 \\
\text { [5] }\end{array}$ & $\begin{array}{l}\text { Belostotsky } \\
2002[11]\end{array}$ & $\begin{array}{c}\text { Peco- } \\
\text { Antic } \\
2006[6]\end{array}$ & $\begin{array}{c}Y u \\
2006[14]\end{array}$ & $\begin{array}{l}\text { Akikusa } \\
2007[18]\end{array}$ & $\begin{array}{c}\text { Cabral } \\
2009[26]\end{array}$ & $\begin{array}{l}\text { Arulkumaran } \\
2011[12]\end{array}$ & $\begin{array}{l}\text { Siomou } \\
2012[13]\end{array}$ & $\begin{array}{c}\text { Krmar } \\
2013[17]\end{array}$ & $\begin{array}{c}\text { Noone } \\
2014[10]\end{array}$ & $\begin{array}{c}\text { Bohm } \\
2014[4]\end{array}$ & $\begin{array}{c}\text { Basu } \\
2015[19]\end{array}$ & $\begin{array}{l}\text { Khalighi } \\
2015 \text { [27] }\end{array}$ & $\begin{array}{c}\text { Sacri } \\
2015[20]\end{array}$ \\
\hline$n=$ & & 5 & 7 & 10 & 31 & 17 & 7 & 20 & 25 & 65 & 8 & 13 & 6 & 40 & 56 & 11 & 21 & 66 \\
\hline $\begin{array}{c}\text { Length } \\
\text { of Follow-Up } \\
\text { (years) }\end{array}$ & & --- & $2 \pm 1$ & $6^{6}$ & $\begin{array}{l}3.75 \pm \\
2.4\end{array}$ & --- & $2.95 \pm 1.9$ & $1.0 \pm 0.43$ & $2.73^{2}$ & --- & 19 & $3.2 \pm 2.9$ & 4.4 & $2.4^{2}$ & --- & $1.74^{2}$ & $2.5^{6}$ & $5.2^{6}$ \\
\hline $\begin{array}{c}\text { Age at } \\
\text { Presentation } \\
\text { (years) }^{1}\end{array}$ & & $11.5 \pm 2.5$ & $13.0 \pm 0.9$ & $12^{6}$ & $\begin{array}{l}11.9 \pm \\
2.9\end{array}$ & 6 & $12.0 \pm 2.6$ & $10.8 \pm 2.8$ & $14.5^{2}$ & $14.2^{2}$ & 11.5 & $13.2 \pm 2.9$ & 10.6 & $12^{2}$ & $11.7^{2}$ & $7.6^{2}$ & $14^{2}$ & $11.5^{6}$ \\
\hline \multirow{2}{*}{ Gender } & $\begin{array}{l}F \\
(\%)\end{array}$ & $4(82)$ & $5(71)$ & $6(60)$ & $27(87)$ & $13(76)$ & $6(86)$ & $18(90)$ & $20(80)$ & $41(63.1)$ & $6(75)$ & $10(77)$ & $5(83)$ & $28(70)$ & $38(68)$ & $6(55)$ & 15 (71) & $55(83)$ \\
\hline & $\begin{array}{l}M \\
(\%)\end{array}$ & 1 (18) & $2(29)$ & $4(4)$ & $4(13)$ & $4(24)$ & $1(14)$ & $2(10)$ & $5(20)$ & $24(36.9)$ & $2(25)$ & $11(23)$ & $1(17)$ & $12(30)$ & $18(32)$ & $5(45)$ & $6(29)$ & $11(17)$ \\
\hline \multirow[b]{3}{*}{ Serology } & $\begin{array}{c}\text { MPO } \\
(\%)\end{array}$ & -- & -- & $10(100)$ & $\begin{array}{c}28 \\
(90.3)\end{array}$ & -- & $7(100)$ & 19 (95) & $4(16)$ & $8(12.3)$ & $2(25)$ & $5(38)$ & $6(100)$ & $10(25)$ & $13(26)$ & $11(100)$ & $10(48)$ & $39(59)$ \\
\hline & $\begin{array}{l}\text { PR3 } \\
\text { (\%) }\end{array}$ & -- & -- & 0 & $3(9.7)$ & -- & 0 & $1(5)$ & $15(60)$ & $44(67.7)$ & $4(50)$ & $7(54)$ & $0(0)$ & $18(45)$ & $34(67)$ & 0 & $7(33)$ & $22(33)$ \\
\hline & Other & $\begin{array}{l}2(40) c- \\
2(40) p- \\
1 \text { unk }\end{array}$ & $\begin{array}{l}4(57) c- \\
3(43) p-\end{array}$ & --- & -- & $\begin{array}{c}10(59) \mathrm{c}- \\
0 \mathrm{p}-\end{array}$ & -- & -- & $\begin{array}{c}\text { Unstated } \\
2(8), \\
\text { ANCA negative } \\
1(4)\end{array}$ & $\begin{array}{c}43(66.2) \mathrm{c}- \\
14(21.5) \mathrm{p}- \\
4 \text { ANCA } \\
\text { negative } \\
1 \text { PR3 \& MPO } \\
\text { positive }\end{array}$ & $\begin{array}{l}\text { Neither } \\
2(25)\end{array}$ & $\begin{array}{c}\text { Neither } \\
1(8)\end{array}$ & -- & $\begin{array}{c}19(47.5) \mathrm{p}- \\
11(27.5) \mathrm{c}- \\
\text { ANCA negative } \\
9(22.5)\end{array}$ & $\begin{array}{c}46(82.7) \\
\text { ANCA } \\
\text { positive }\end{array}$ & 10 (91) p- & $\begin{array}{l}3 \text { neg; } \\
1 \text { unk. }\end{array}$ & $\begin{array}{l}43(65) \mathrm{c}- \\
22(33) \mathrm{p}- \\
1 \text { (2) both }\end{array}$ \\
\hline $\begin{array}{l}\text { Patients with } \\
\text { Renal } \\
\text { Involvement } \\
\text { (\%) }\end{array}$ & & $5(100)$ & $7(100)$ & $6(60)$ & $\begin{array}{c}31 \\
(100)\end{array}$ & $9(53)$ & $7(100)$ & $20(100)$ & $22(88)$ & $49(75.4)$ & $5(63)$ & $13(100)$ & $6(100)$ & $40(100)$ & $23(82)$ & $11(100)$ & $21(100)$ & $58(88)$ \\
\hline $\begin{array}{l}\text { Dialysis at } \\
\text { Presentation } \\
\text { (\%) }\end{array}$ & & --- & $2(29)$ & --- & $7(23)$ & $1(6)$ & $2(29)$ & $5(25)$ & $5(20)$ & -- & $1(12.5)$ & $1(8)$ & 1 (17) & $12(30)$ & -- & $9(82)$ & -- & $9(14)$ \\
\hline $\begin{array}{l}\text { Development } \\
\text { of ESRD } \\
\text { (\%) }\end{array}$ & & -- & 1 (14) & $4(40)$ & $9(29)$ & $1(6)$ & $2(29)$ & $10(50)$ & $3(12)$ & -- & $1(12.5)$ & $3(23)$ & 0 & $14(35)$ & -- & 0 & $7(37)$ & $22(34)$ \\
\hline
\end{tabular}

Table 3: Summary of Literature Reported on Pediatric ANCA-Associated Vasculitis

\footnotetext{
${ }^{1}$ Reported as mean unless otherwise noted

${ }^{2}$ Reported as median

$---=$ not available
} 





Figure 1: Systemic Symptoms at Presentation of Patients with ANCA-Positive Glomerulonephritis 


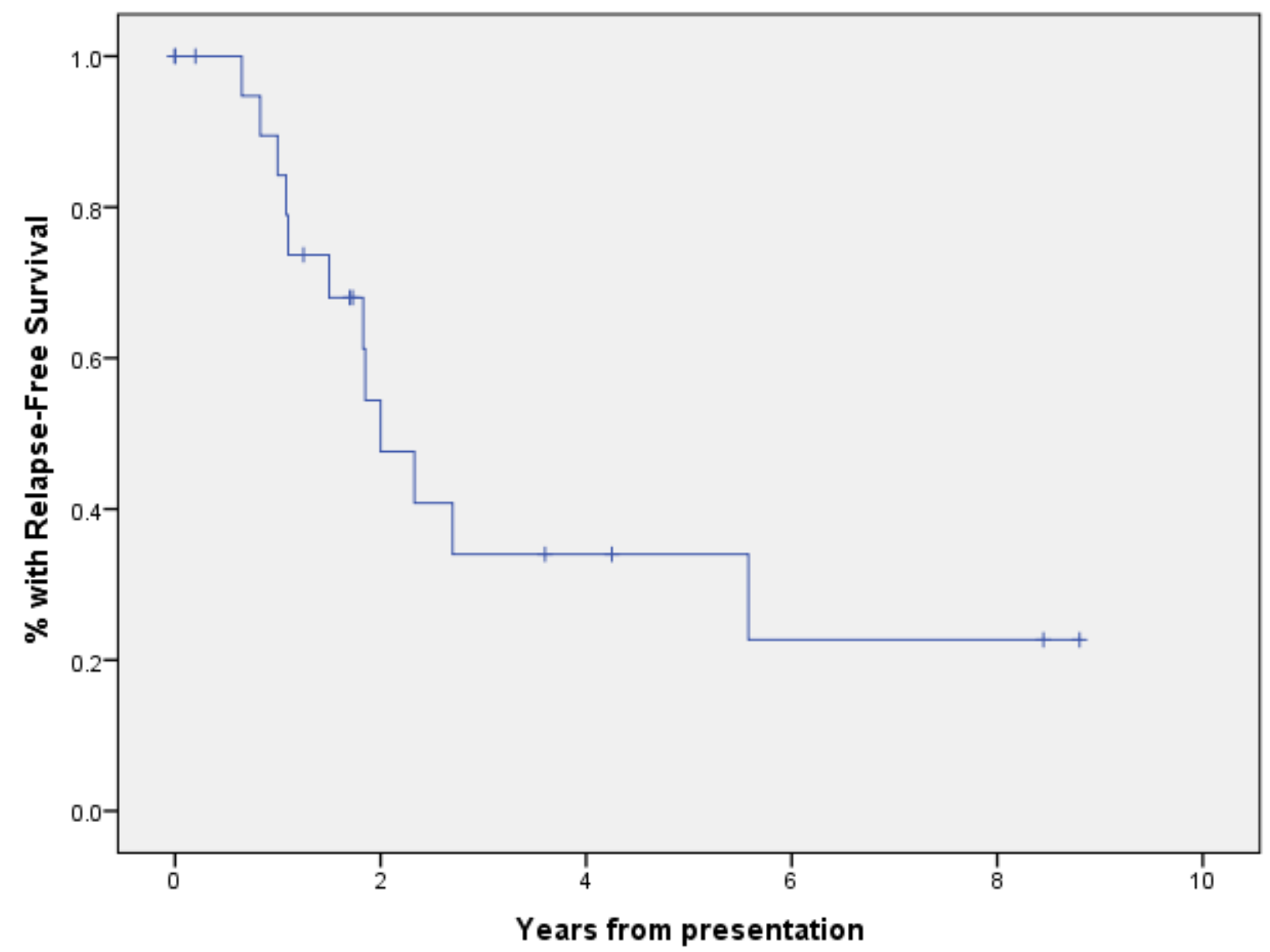

Figure 2: Kaplan-Meier Curve Illustrating Relapse-Free Survival For Patients with First-Time Clinical or Serologic Relapse 




Figure 1: Systemic Symptoms at Presentation of Patients with ANCA-Positive Glomerulonephritis 


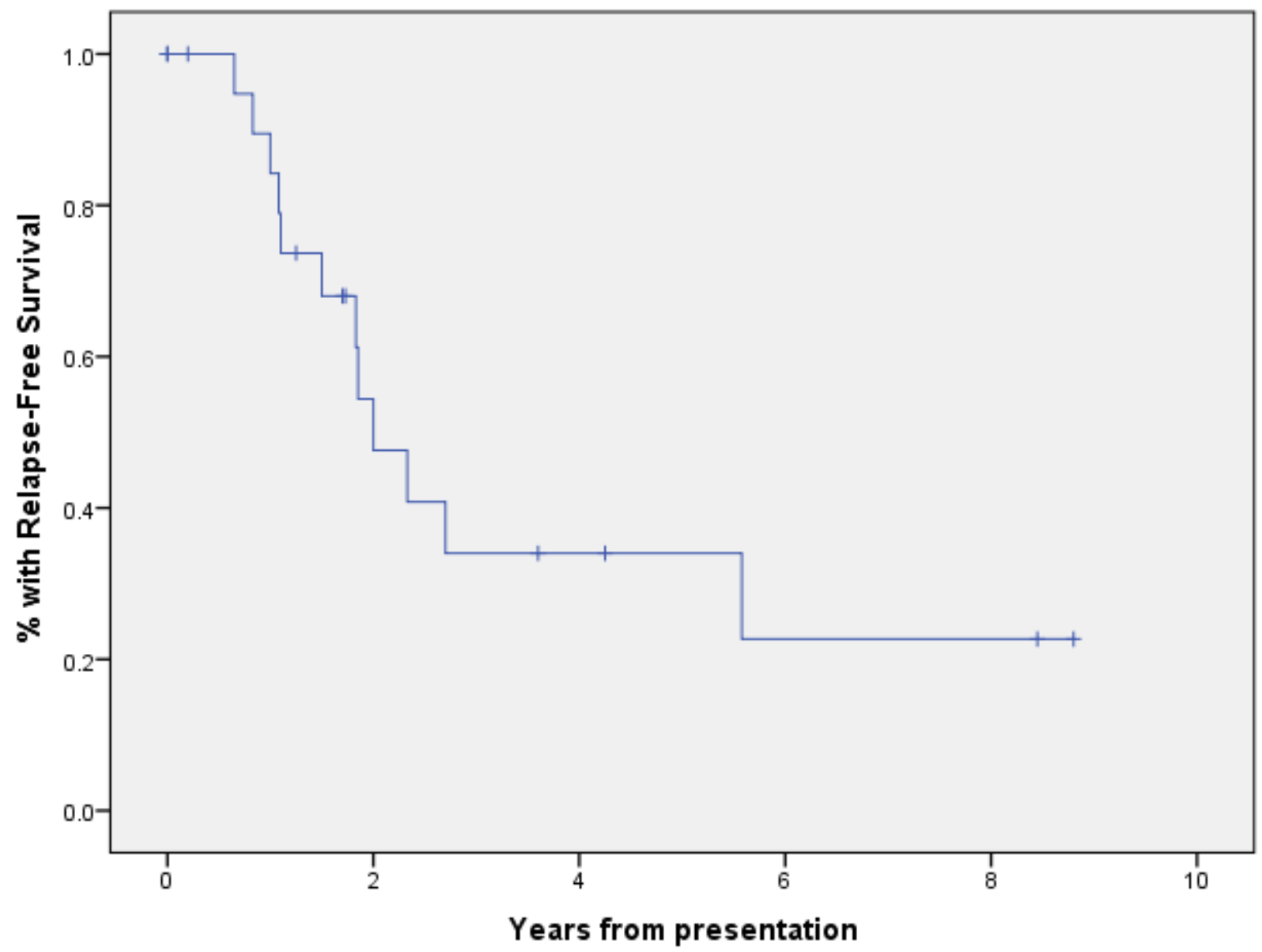

Figure 2: Kaplan-Meier Curve Illustrating Relapse-Free Survival For Patients with First-Time Clinical or Serologic Relapse 


\begin{tabular}{ll}
\multicolumn{1}{l}{ Gender $[\mathrm{n}(\%)]$} \\
${ } }$ & $9(41)$ \\
\hline Female & $13(59)$ \\
Age (Median in years) & $13.7(\mathrm{IQR} 4.2)$ \\
\hline Male & $15.6(\mathrm{IQR} 3.6)$ \\
\hline Female & $11.9(\mathrm{IQR} 4.8)$
\end{tabular}

Serology $[\mathrm{n}(\%)]$
\begin{tabular}{ll}
$\mathrm{c}-\mathrm{ANCA} / \mathrm{PR} 3$ & $9(41)$ \\
\hline p-ANCA/MPO & $9(41)$ \\
\hline $\mathrm{c}-\mathrm{ANCA}$ & $0(0)$ \\
p-ANCA & $1(4.5)$ \\
\hline PR3 & $0(0)$ \\
\hline MPO & $1(4.5)$ \\
\hline Both & $1(4.5)$ \\
\hline Other & $1(4.5)$ \\
\hline
\end{tabular}

Median BUN

$\underline{(\mathrm{mg} / \mathrm{dL})}$

$40.5(\mathrm{IQR} 52)^{1}$

Median Creatinine

$\underline{(\mathrm{mg} / \mathrm{dL})}$ $2.7(\mathrm{IQR} 5.4)^{2}$

\% with Hematuria $\quad 100 \%$

$\%$ with Proteinuria $\quad 100 \%$

Median Protein:Creatinine

$\underline{(\mathrm{mg} / \mathrm{mg})}$

$1.5(\mathrm{IQR} 4.1)^{3}$

Pathologic Findings on Biopsy $[\mathrm{n}(\%)]^{4}$

Focal $\quad 0(0)$

Crescentic $10(53)$

Mixed $4(21)$

Sclerotic $5(26)$

Table 1: Summary of Patient Characteristics at Presentation

${ }^{1} 20$ of 22 patients have BUN reported at presentation

221 of 22 patients have creatinine reported at presentation

${ }^{3} 14$ of 22 patients have $\mathrm{Pr} / \mathrm{Cr}$ ratios reported at presentation

${ }^{4} 2$ biopsies at outside institutions not included in classification 


\begin{tabular}{|c|c|}
\hline CKD $1\left(\right.$ eGFR $\left.>90 \mathrm{~mL} / \mathrm{min} / 1.73 \mathrm{~m}^{2}\right)$ & 6 \\
\hline CKD 2 (eGFR 60-89 mL/min/1.73m²) & 3 \\
\hline CKD 3 (eGFR 30-59 mL/min/1.73m²) & 3 \\
\hline $\begin{array}{c}\text { CKD 5/ESRD/Tx }(\text { eGFR }<15 \\
\left.\mathrm{mL} / \mathrm{min} / 1.73 \mathrm{~m}^{2} \text { or dialysis }\right)\end{array}$ & 7 \\
\hline Lost to follow-up & 2 \\
\hline Deceased & 1 \\
\hline TOTAL & 22 \\
\hline
\end{tabular}

Table 2: Renal Outcomes at Median Follow-up of 5.8 years 


\begin{tabular}{|c|c|c|c|c|c|c|c|c|c|c|c|c|c|c|c|c|c|c|}
\hline & & $\begin{array}{c}\text { Ellis } \\
1995[23]\end{array}$ & $\begin{array}{l}\text { Valentini } \\
1998[21]\end{array}$ & $\begin{array}{c}\text { Bakkaloglu } \\
2001 \text { [25] }\end{array}$ & $\begin{array}{l}\text { Hattori } \\
2001 \\
{[5]}\end{array}$ & $\begin{array}{l}\text { Belostotsky } \\
2002[11]\end{array}$ & $\begin{array}{l}\text { Peco- } \\
\text { Antic } \\
2006 \text { [6] }\end{array}$ & $\begin{array}{c}\mathrm{Yu} \\
2006[14]\end{array}$ & $\begin{array}{l}\text { Akikusa } \\
2007[18]\end{array}$ & $\begin{array}{c}\text { Cabral } \\
2009[26]\end{array}$ & $\begin{array}{c}\text { Arulkumaran } \\
2011[12]\end{array}$ & $\begin{array}{c}\text { Siomou } \\
2012[13]\end{array}$ & $\begin{array}{c}\text { Krmar } \\
2013[17]\end{array}$ & $\begin{array}{c}\text { Noone } \\
2014[10]\end{array}$ & $\begin{array}{l}\text { Bohm } \\
2014 \text { [4] }\end{array}$ & $\begin{array}{c}\text { Basu } \\
2015 \text { [19] }\end{array}$ & $\begin{array}{l}\text { Khalighi } \\
2015 \text { [27] }\end{array}$ & $\begin{array}{c}\text { Sacri } \\
2015[20]\end{array}$ \\
\hline$n=$ & & 5 & 7 & 10 & 31 & 17 & 7 & 20 & 25 & 65 & 8 & 13 & 6 & 40 & 56 & 11 & 21 & 66 \\
\hline $\begin{array}{c}\text { Length } \\
\text { of Follow-Up } \\
\text { (years) }\end{array}$ & & --- & $2 \pm 1$ & $6^{6}$ & $\begin{array}{c}3.75 \pm \\
2.4 \\
\end{array}$ & --- & $2.95 \pm 1.9$ & $1.0 \pm 0.43$ & $2.73^{2}$ & --- & 19 & $3.2 \pm 2.9$ & 4.4 & $2.4^{2}$ & --- & $1.74^{2}$ & $2.5^{6}$ & $5.2^{6}$ \\
\hline $\begin{array}{c}\text { Age at } \\
\text { Presentation } \\
\text { (years) }^{1}\end{array}$ & & $11.5 \pm 2.5$ & $13.0 \pm 0.9$ & $12^{6}$ & $\begin{array}{c}11.9 \pm \\
2.9\end{array}$ & 6 & $12.0 \pm 2.6$ & $10.8 \pm 2.8$ & $14.5^{2}$ & $14.2^{2}$ & 11.5 & $13.2 \pm 2.9$ & 10.6 & $12^{2}$ & $11.7^{2}$ & $7.6^{2}$ & $14^{2}$ & $11.5^{6}$ \\
\hline \multirow{2}{*}{ Gender } & $\begin{array}{c}F \\
(\%)\end{array}$ & $4(82)$ & $5(71)$ & $6(60)$ & $27(87)$ & $13(76)$ & $6(86)$ & $18(90)$ & $20(80)$ & $41(63.1)$ & $6(75)$ & $10(77)$ & $5(83)$ & $28(70)$ & $38(68)$ & $6(55)$ & $15(71)$ & $55(83)$ \\
\hline & $\begin{array}{l}M \\
(\%)\end{array}$ & 1 (18) & $2(29)$ & $4(4)$ & $4(13)$ & $4(24)$ & 1 (14) & $2(10)$ & $5(20)$ & $24(36.9)$ & 2 (25) & $11(23)$ & $1(17)$ & $12(30)$ & $18(32)$ & $5(45)$ & $6(29)$ & $11(17)$ \\
\hline \multirow[b]{3}{*}{ Serology } & $\begin{array}{l}\text { MPO } \\
(\%)\end{array}$ & --- & --- & $10(100)$ & $\begin{array}{c}28 \\
(90.3)\end{array}$ & --- & $7(100)$ & $19(95)$ & $4(16)$ & $8(12.3)$ & $2(25)$ & $5(38)$ & $6(100)$ & $10(25)$ & $13(26)$ & $11(100)$ & $10(48)$ & $39(59)$ \\
\hline & $\begin{array}{l}\text { PR3 } \\
(\%)\end{array}$ & -- & -- & 0 & $3(9.7)$ & -- & 0 & $1(5)$ & $15(60)$ & $44(67.7)$ & $4(50)$ & $7(54)$ & $0(0)$ & $18(45)$ & $34(67)$ & 0 & $7(33)$ & $22(33)$ \\
\hline & Other & $\begin{array}{l}2(40) c- \\
2(40) p- \\
1 \text { unk }\end{array}$ & $\begin{array}{l}4(57) c- \\
3(43) p-\end{array}$ & --- & --- & $\begin{array}{c}10(59) \mathrm{c}- \\
0 \mathrm{p}-\end{array}$ & --- & --- & $\begin{array}{c}\text { Unstated } \\
2(8), \\
\text { ANCA negative } \\
1(4)\end{array}$ & $\begin{array}{c}43(66.2) \mathrm{c}- \\
14(21.5) \mathrm{p}- \\
4 \text { ANCA } \\
\text { negative } \\
1 \text { PR3 \& MPO } \\
\text { positive } \\
\end{array}$ & $\begin{array}{l}\text { Neither } \\
2(25)\end{array}$ & $\begin{array}{l}\text { Neither } \\
1(8)\end{array}$ & -.- & $\begin{array}{c}19(47.5) p- \\
11(27.5) c- \\
\text { ANCA negative } \\
9(22.5)\end{array}$ & $\begin{array}{l}46(82.7) \\
\text { ANCA } \\
\text { positive }\end{array}$ & 10 (91) p- & $\begin{array}{l}3 \text { neg; } \\
1 \text { unk. }\end{array}$ & $\begin{array}{l}43(65) \mathrm{c}- \\
22(33) \mathrm{p}- \\
1 \text { (2) both }\end{array}$ \\
\hline $\begin{array}{l}\text { Patients with } \\
\text { Renal } \\
\text { Involvement } \\
\text { (\%) }\end{array}$ & & $5(100)$ & $7(100)$ & $6(60)$ & $\begin{array}{c}31 \\
(100)\end{array}$ & $9(53)$ & $7(100)$ & $20(100)$ & $22(88)$ & $49(75.4)$ & $5(63)$ & $13(100)$ & $6(100)$ & $40(100)$ & $23(82)$ & $11(100)$ & $21(100)$ & $58(88)$ \\
\hline $\begin{array}{l}\text { Dialysis at } \\
\text { Presentation } \\
\text { (\%) }\end{array}$ & & --- & $2(29)$ & --- & $7(23)$ & $1(6)$ & $2(29)$ & $5(25)$ & $5(20)$ & -- & $1(12.5)$ & $1(8)$ & $1(17)$ & $12(30)$ & --- & $9(82)$ & --- & $9(14)$ \\
\hline $\begin{array}{c}\text { Development } \\
\text { of ESRD } \\
(\%)\end{array}$ & & --- & 1 (14) & $4(40)$ & $9(29)$ & $1(6)$ & $2(29)$ & $10(50)$ & $3(12)$ & --- & $1(12.5)$ & $3(23)$ & 0 & $14(35)$ & --- & 0 & $7(37)$ & $22(34)$ \\
\hline
\end{tabular}

Table 3: Summary of Literature Reported on Pediatric ANCA-Associated Vasculitis

${ }^{1}$ Reported as mean unless otherwise noted

${ }^{2}$ Reported as median

--- = not available 